\title{
Comparison of the IHC, FISH, SISH and qPCR methods for the molecular diagnosis of breast cancer
}

\author{
D. TVRDÍK, L. STANĚK, H. SKÁLOVÁ, P. DUNDR, Z. VELENSKÁ and C. POVÝŠIL \\ Institute of Pathology, 1st Faculty of Medicine, Charles University \\ and General University Hospital, 12800 Prague 2, Czech Republic
}

Received February 8, 2012; Accepted May 15, 2012

DOI: $10.3892 / \mathrm{mmr} .2012 .919$

\begin{abstract}
Her 2 proto-oncogene amplification and protein overexpression is observed in $20-40 \%$ of patients with breast cancer and plays a crucial role in invasive breast cancer and its treatment. In the present study, we investigated samples from 131 patients with invasive breast carcinoma. In all cases, the overexpression/amplification level of Her2 was determined using manual immunohistochemistry (IHC) and/or automatic IHC, fluorescence in situ hybridization (FISH), silver in situ hybridization (SISH) and quantitative polymerase chain reaction (qPCR). Using various methods, we demonstrated candidate methods for Her2 detection and their dependability. Our results demonstrate that these methods are highly comparable for the detection of Her2 overexpression/amplification. It was also revealed that qPCR is a valuable tool for the evaluation of Her2 gene overexpression/amplification. The results from pPCR analysis positively correlated with the results from IHC and FISH analysis. Moreover, in contrast to IHC or SISH/ FISH, the results obtained by qPCR were not encumbered with any subjective error on the part of the evaluator.
\end{abstract}

\section{Introduction}

Her2 proto-oncogene amplification and protein overexpression is observed in $20-40 \%$ of patients with breast cancer (1), and plays a crucial role in the biological behavior and pathogenesis of invasive breast cancer and its treatment. Both node-positive and node-negative breast cancer patients whose tumors exhibit Her2 amplification have a poor prognosis, increased risk of recurrence and high risk of disease-related mortality, demonstrating an overall shorter survival time (2-6).

The Her2 gene [also known as ERBB2 or epidermal grow th factor receptor (EGFR)2] encodes a $185 \mathrm{kDa}$ trans-

Correspondence to: Dr Daniel Tvrdík, Institute of Pathology, 1st Faculty of Medicine, Charles University and General University Hospital, Studničkova 2, 12800 Prague 2, Czech Republic

E-mail: daniel.tvrdik@vfn.cz

Key words: breast cancer, Her2, immunohistochemistry, fluorescence in situ hybridization, silver in situ hybridization, quantitative polymerase chain reaction membrane glycoprotein with tyrosine kinase activity. Her2 has high sequence homology with other members of the EGFR family (7). The function of these receptors is the regulation of cell growth, differentiation and survival. Receptor activation requires 3 components: a ligand, a receptor and a dimerization partner. When a specific ligand binds to a Her2 receptor, it must combine with another receptor of similar structure and undergo dimerization. This initiates a cascade of phosphorylation and signal transduction events that affect the transcription of specific genes involved in cell proliferation and survival (8).

However, Her2 status does predict a favorable response to chemotherapy and anti-Her2 antibody treatment (9), since the humanized anti-Her2 antibody binds to the Her2 receptor, thereby preventing heterodimerization and interrupting the downstream signaling pathway. Moreover, the bound antibody induces FcR-mediated cytotoxicity (8). Therefore, it is extremely important to determine the status of Her 2 when considering biological therapy.

In the present study, we investigated samples from 131 patients with invasive breast carcinoma. The expression/ amplification level of Her2 was evaluated using manual and/or automatic immunohistochemistry (IHC), fluorescence in situ hybridization (FISH), silver in situ hybridization (SISH) and quantitative polymerase chain reaction (qPCR).

\section{Patients and methods}

Patients. Our study included 131 female patients, aged $55 \pm 14$ years (mean \pm standard deviation), treated for breast carcinoma at the General Faculty Hospital (Prague, Czech Republic) between 2005 and 2011. In all cases, tumor tissue was obtained from a diagnostic core needle biopsy or from a specimen removed during final surgery (lumpectomy or mastectomy).

Histological evaluation. The specimens obtained from the core needle biopsy and surgery were fixed in $10 \%$ formalin and embedded in paraffin wax. Histological evaluation was performed on slides routinely stained with hematoxylin and eosin (H\&E). Tumor stage was determined according to WHO guidelines (2003) regarding the use of clinical data.

Immunohistochemistry. Immunohistochemistry included the assessment of Her2 by manual and automatic procedures. 
The manual evaluation of Her2 was conducted using HerceptTest (DakoCytomation, Glostrup, Denmark) according to the manufacturer's instructions. The slides were immersed in a pre-heated epitope retrieval solution $\left(95-99^{\circ} \mathrm{C}\right)$ in a water bath for $40 \mathrm{~min}$, cooled at room temperature for $20 \mathrm{~min}$ and then rinsed using a washing buffer. A peroxidase-blocking reagent, a primary antibody, a visualization reagent and a substrate-chromogen solution were applied; the slides were incubated and after each step they were rinsed with a washing buffer. The evaluation of Her2 overexpression was performed as defined by the HercepTest scoring guidelines: 0 , no staining or membrane staining in less than $10 \%$ of the tumor cells; $1+$, partial faint membrane staining in more than $10 \%$ of the tumor cells; $2+$, weak to moderate complete membrane staining in more than $10 \%$ of the tumor cells; $3+$, strong complete membrane staining in more than $10 \%$ of the tumor cells. The HercepTest results were interpreted as negative (score 0 and $1+$ ), weakly positive (2+) and strongly positive (3+) for Her2 protein overexpression.

Automatic Her2 staining was performed using Ventana anti-Her2/neu rabbit monoclonal antibody (Roche Diagnostics, Mannheim, Germany) using a Ventana Benchmark XT instrument (Roche Diagnostics) according to the manufacturer's instructions. Briefly, primary antibody incubation was carried out at $37^{\circ} \mathrm{C}$ for $16 \mathrm{~min}$, then with UV HRP UNIV MULT for $8 \mathrm{~min}, \mathrm{UV}$ DAB and UV DAB $\mathrm{H}_{2} \mathrm{O}_{2}$ for $8 \mathrm{~min}$, UV COPPER for $4 \mathrm{~min}$, hematoxylin for $8 \mathrm{~min}$ and bluing reagent for $8 \mathrm{~min}$. The interpretation of Ventana staining was the same as that for the HercepTest.

Fluorescence in situ hybridization. Sections $(5 \mu \mathrm{m})$ of paraffin-embedded tissue were processed for FISH using the PathVysion HER-2 DNA Probe kit from Abbott Vysis (Downers Grove, IL, USA). The assay procedure was conducted according to the manufacturer's instructions. Firstly, the slides were deparaffinized in xylene, then pre-treated in $0.2 \mathrm{~N} \mathrm{HCl}$ and subsequently in an $\mathrm{NaSCN}$ solution at $80^{\circ} \mathrm{C}$; the next step was proteolytic treatment. The protease digestion was performed to obtain readable and conclusive FISH results. Protease II (25 mg; Abbott Vysis) in a $50 \mathrm{ml}$ saline solution at $\mathrm{pH} 2.0$ was used with a digestion time of $45 \mathrm{~min}$ for the core needle biopsy and $60 \mathrm{~min}$ for the final surgery samples. Next, the sections were fixed in buffered formalin. We then applied the FISH probe, sealed it with liquid rubber cement, co-denatured the specimen and the DNA probe for $1 \mathrm{~min}$ at $85^{\circ} \mathrm{C}$ and then hybridized it overnight in a ThermoBrite system (Abbott Vysis) at $37^{\circ} \mathrm{C}$. After hybridization, the unbound probe was removed in $0.4 \mathrm{xSSC} / 0.3 \% \mathrm{NP}-40$ washing solution at $74^{\circ} \mathrm{C}$, and the slides were dehydrated and counterstained with 4,6-diamidino-2-phenylindol (DAPI).

For each sample, a minimum of 20 cells was evaluated using an Olympus Provis AX70 microscope (Olympus, Tokyo, Japan) for the presence of amplification signals. A positive result was defined as the ratio, Her2:CEP17 >2.

Silver in situ hybridization. The automatic silver in situ hybridization of Her2 was conducted using a Ventana Inform Her2 Dual ISH DNA Probe Cocktail assay (Roche) according to the manufacturer's instructions. The SISH conditions for the Ventana Benchmark XT (Roche Diagnostics) instrument were: cell conditioner 2 for $8 \mathrm{~min}$, protease 3 for $16 \mathrm{~min}$, hybridization for $6 \mathrm{~h}$, washing at $72^{\circ} \mathrm{C}$, silver staining for $8 \mathrm{~min}$, red staining for $8 \mathrm{~min}$, hematoxylin staining for $8 \mathrm{~min}$ and bluing reagent for $4 \mathrm{~min}$. The interpretation of Ventana SISH staining was the same as that for manual FISH.

DNA isolation and $q P C R$ analysis. Deparaffinized slides of formalin-fixed, paraffin-embedded tissue and isolation of DNA were performed using standard procedures. First, the slides were deparaffinized in xylene and the DNA was then extracted using a QIAamp DNA mini kit (Qiagen, Hamburg, Germany).

Her2 amplification levels were quantified by using a LightCycler 480 (Roche Diagnostics) and the LightMix Her2/ neu kit (Tib MolBiol GmbH, Berlin, Germany) according to manufacturer's instructions. The kit contained a DNA calibrator provided to generate a calibration curve.

The PCR conditions were: initial denaturation for $10 \mathrm{~min}$ at $95^{\circ} \mathrm{C}$, followed by 50 cycles of denaturation for $10 \mathrm{sec}$ at $95^{\circ} \mathrm{C}$, annealing for $10 \mathrm{sec}$ at $60^{\circ} \mathrm{C}$ and extension for $10 \mathrm{sec}$ at $72^{\circ} \mathrm{C}$.

The level of Her2 DNA was normalized to the level of the housekeeping gene, ribosomal protein L23 (RPL23). PCR amplification of each transcript was performed twice. The normalized ratio, Her2:RPL23 $>2$, was considered positive for Her2 gene amplification.

\section{Results}

Initially, we determined the Her 2 status of 29 patients by immunohistochemistry and qPCR analysis (Table I). The patients included 12 Her2-negative patients (score 0 or $1+$ ), 2 patients with weak positivity (score $2+$ ) and 15 patients with a strong membrane positivity $(3+)$. We found a positive correlation $(\mathrm{R}=0.57)$ between immunohistochemically detected membrane protein expression and molecular biologically analyzed Her2 gene amplification using qPCR. In a group of 11 patients, we determined Her2 status by using qPCR and FISH methods; this group included 1 Her2-negative patient (score 0), 1 patient with weak positivity (score $2+$ ) and 9 patients with $3+$ positivity. We found a positive correlation $(\mathrm{R}=0.51)$ between the results obtained from these 2 methods.

In the following step, we performed analysis of Her2 status by manual and automatic IHC and FISH in another group of 35 patients (Table II). This group included 16 Her2-negative patients (score 0 or $1+$ ), 8 patients with weak positivity (score $2+$ ) and 11 patients with a strong membrane positivity $3+$. We found a significant correlation between the results obtained from manual and automatic IHC $(\mathrm{R}=0.9)$ and between those obtained from manual IHC and FISH $(\mathrm{R}=0.81)$.

Finally, we analyzed another group of 67 patients using automatic IHC and SISH (Table III). This group included 51 Her2-negative patients (score 0 or $1+$ ), 10 patients with weak positivity (score $2+$ ) and 6 patients with a strong membrane positivity $3+$. We found a positive correlation $(R=0.72)$ between the results obtained from automatic IHC and SISH.

However, the correlation co-efficient (R) calculated from these methods was, in some cases, low, as qPCR enables a wide range of real-time applications compared to other methods that score from 0 to $3+$. 
Table I. Results of the detection of Her2 using manual IHC, FISH and qPCR methods.

\begin{tabular}{|c|c|c|c|}
\hline Patient no. & IHC & FISH & qPCR \\
\hline 1 & 0 & 1.58 & 0.86 \\
\hline 2 & $3+$ & 4.01 & 17.86 \\
\hline 3 & $3+$ & 4.97 & 25.0 \\
\hline 4 & $2+$ & 1.52 & 1.91 \\
\hline 5 & $3+$ & 1.89 & 0.62 \\
\hline 6 & $3+$ & 5.8 & 7.9 \\
\hline 7 & $3+$ & 4.1 & 6.09 \\
\hline 8 & $3+$ & 5.3 & 3.09 \\
\hline 9 & $3+$ & 2.7 & 3.01 \\
\hline 10 & $3+$ & 2.32 & 19.0 \\
\hline 11 & $3+$ & 6.4 & 21.07 \\
\hline 12 & $3+$ & N/A & 9.84 \\
\hline 13 & 0 & N/A & 0.25 \\
\hline 14 & $1+$ & N/A & 0.74 \\
\hline 15 & 0 & N/A & 0.21 \\
\hline 16 & 0 & N/A & 1.05 \\
\hline 17 & $3+$ & N/A & 27.8 \\
\hline 18 & 0 & N/A & 0.80 \\
\hline 19 & 0 & N/A & 0.54 \\
\hline 20 & $2+$ & N/A & 1.5 \\
\hline 21 & $3+$ & N/A & 4.52 \\
\hline 22 & 0 & N/A & 0.9 \\
\hline 23 & $3+$ & N/A & 3.25 \\
\hline 24 & 0 & N/A & 0.21 \\
\hline 25 & $1+$ & N/A & 1.6 \\
\hline 26 & 0 & N/A & 0.23 \\
\hline 27 & 0 & N/A & 0.11 \\
\hline 28 & $3+$ & N/A & 3.25 \\
\hline 29 & $3+$ & N/A & 3.03 \\
\hline
\end{tabular}

The level of Her2 amplification was provided as the normalized ratio, Her2/CEP17 or Her2/ribosomal protein L23 (RPL23). IHC, immunohistochemistry; FISH, fluorescence in situ hybridization; qPCR, quantitative PCR; N/A, not available.

We can conclude that our proposed method of detecting the amplification/overexpression Her2 using the qPCR appears to be sufficiently specific with good reproducibility. Moreover, our data demonstrated that all methods investigated were highly comparable for the detection of Her2 overexpression/ amplification.

\section{Discussion}

Clinicians have long recognized the heterogeneity of human breast cancers, not only in terms of their diverse natural histories, despite identical morphological features, but also in their varied responses to treatment (10).

With the development of tailored therapies targeting specific molecules, Her2, ER and other molecular markers have become important predictive factors. For example, Her2
Table II. Results of the detection of Her2 using manual and automatic IHC and FISH methods.

\begin{tabular}{|c|c|c|c|}
\hline Patient no. & IHC (HercepTest) & IHC (Ventana) & FISH \\
\hline 1 & 0 & $1+$ & 1.00 \\
\hline 2 & 0 & $1+$ & 1.00 \\
\hline 3 & 0 & $1+$ & 1.00 \\
\hline 4 & 0 & 0 & 1.00 \\
\hline 5 & 0 & $1+$ & 1.00 \\
\hline 6 & 0 & $1+$ & 1.00 \\
\hline 7 & 0 & $1+$ & 1.00 \\
\hline 8 & 0 & $1+$ & 1.20 \\
\hline 9 & 0 & $1+$ & 1.20 \\
\hline 10 & 0 & 0 & 1.00 \\
\hline 11 & $1+$ & 0 & 1.13 \\
\hline 12 & $1+$ & $2+$ & 1.00 \\
\hline 13 & $1+$ & $1+$ & 1.00 \\
\hline 14 & $1+$ & $1+$ & 1.50 \\
\hline 15 & $1+$ & $1+$ & 1.00 \\
\hline 16 & $1+$ & $1-2+$ & 1.12 \\
\hline 17 & $2+$ & $2+$ & 1.31 \\
\hline 18 & $2+$ & $2+$ & 3.26 \\
\hline 19 & $2+$ & $2+$ & 1.00 \\
\hline 20 & $2+$ & $2-3+$ & 1.12 \\
\hline 21 & $2+$ & $2+$ & 1.76 \\
\hline 22 & $2+$ & $2+$ & 1.06 \\
\hline 23 & $2+$ & $2+$ & 2.30 \\
\hline 24 & $2+$ & $3+$ & 6.10 \\
\hline 25 & $3+$ & $3+$ & 6.40 \\
\hline 26 & $3+$ & $3+$ & 6.81 \\
\hline 27 & $3+$ & $3+$ & 6.31 \\
\hline 28 & $3+$ & $2+$ & 4.81 \\
\hline 29 & $3+$ & $3+$ & 3.00 \\
\hline 30 & $3+$ & $3+$ & 5.42 \\
\hline 31 & $3+$ & $3+$ & 4.68 \\
\hline 32 & $3+$ & $3+$ & 4.90 \\
\hline 33 & $3+$ & $3+$ & 6.61 \\
\hline 34 & $3+$ & $3+$ & 4.60 \\
\hline 35 & $3+$ & $3+$ & 6.40 \\
\hline
\end{tabular}

The level of Her2 amplification was provided as the normalized ratio, Her2/CEP17. IHC, immunohistochemistry; FISH, fluorescence in situ hybridization; N/A, not available

positivity predicts a response to trastuzumab, and estrogen receptor positivity predicts response to hormonal therapy (11).

Her2 protein overexpression is also indicative of a more aggressive tumor phenotype, an increased number of lymph node metastases, a shorter time to treatment failure and a shorter overall survival time (1,3-6). Moreover, through unknown mechanisms, it correlates with grade and type of breast cancer and is associated with a poor prognosis (12).

The most common methods for examining Her2 status are IHC, for the detection of gene expression at the protein level, 
Table III. Results of the detection of Her2 using automatic IHC and SISH methods.

\begin{tabular}{|c|c|c|c|c|c|}
\hline & \multirow{2}{*}{ Patient no. } & \multirow{2}{*}{ IHC } & \multirow{2}{*}{ SISH } \\
\hline Patient no. & IHC & SISH & & & \\
\hline & & & 52 & $1+$ & 1.1 \\
\hline 1 & $1+$ & 1.98 & 53 & $1+$ & 1 \\
\hline 2 & $2+$ & 1.55 & 54 & $2+$ & 1.8 \\
\hline 3 & $1+$ & 1.35 & 55 & $2+$ & 1.93 \\
\hline 4 & $1+$ & 1 & 56 & 0 & 1 \\
\hline 5 & $1+$ & 1 & 57 & $3+$ & 1.9 \\
\hline 6 & 0 & 1.13 & 58 & $3+$ & 1.65 \\
\hline 7 & $1+$ & 1.05 & 59 & 0 & 1 \\
\hline 8 & 0 & 1.05 & 60 & $2+$ & 2 \\
\hline 9 & $1+$ & 1.1 & 61 & $3+$ & 1.8 \\
\hline 10 & $1+$ & 1 & 62 & $2+$ & 2.2 \\
\hline 11 & 0 & 1 & 63 & $3+$ & 2.1 \\
\hline 12 & $1+$ & 1 & 64 & $2+$ & 1.7 \\
\hline 13 & 0 & 1.1 & 65 & $1+$ & 1.1 \\
\hline 14 & $1+$ & 1.54 & 66 & 0 & 1.2 \\
\hline 15 & $2+$ & 1 & 67 & $3+$ & 1.7 \\
\hline
\end{tabular}

1.45

1.22

1.1

1

1.03

1

1

1.3

1

1

1

1.12

1

1

1.7

1.6

1

1

1.02

1

1.07

1.25

1

1.51

1

1.54

1.62

1.05

1.3

1.8

1.1

1

1.63

1.6

1.7

The level of Her2 amplification was provided as a normalized ratio, Her2/CEP17. IHC, immunohistochemistry; SISH, silver in situ hybridization; N/A, not available.

and FISH, for the detection of gene amplification on the DNA level.

Immunohistochemical evaluation can be affected by variations among antibodies, fixatives and subjective interpretation. No significant difference was identified between the manual Herceptest and the automatic Ventana method. However, the automatic Ventana method stained a little more intensely than the HercepTest method; this would not be a problem for an experienced pathologist.

In situ hybridization techniques allow the analysis of individual cells, and can detect whether amplification is the result of chromosome duplication or gene amplification. However, FISH is expensive, time-consuming and requires several hours for hybridization (often overnight) and considerable time to count amplification in individual cells. Moreover, FISH/SISH cannot identify cases in which the gene product is overexpressed in the absence of gene amplification.

Again, no significant difference was identified between the manual FISH and the automatic SISH methods. However, in cases of strong amplification, the overlapping SISH signals may aggregate in clusters that cannot be individually counted. Although this is not a problem for clinical use, it may cause problems with strict external quality assessment.

qPCR techniques allow the detection of Her2 on DNA and RNA (13) levels, and may provide alternatives to these methods $(14,15)$. In the future, PCR methods are likely to become more widely used as they are more sensitive, faster, easy to perform and allow the screening of multiple samples at the same time. On the other hand, the use of formalin-fixed paraffin-embedded tissue for this purpose on the RNA level may be problematic since the RNA often becomes degraded in this material (16). 
In conclusion, we determined Her2 status using several methods including manual and automatic IHC, SISH/FISH and qPCR. We verified that these methods produce mutual results and are therefore interchangeable.

We conclude that in order to devise effective rational treatments for Her2-positive tumors, a reliable tool for determining Her2 status is required. This study demonstrates that qPCR is a valuable tool for the evaluation of Her2 gene overexpression. The results from qPCR analysis positively correlated with the results obtained from IHC and FISH analysis. Moreover, the results obtained by qPCR are not encumbered with any subjective error on the part of the evaluator.

\section{Acknowledgements}

This study was supported by grant IGA MZ ČR NS/10575-3. We wish to thank Lenka Matiášková, Jana Š́dlová and Blanka Véghová for their precise laboratory technician work.

\section{References}

1. Slamon DJ, Godolphin W, Jones LA, et al: Studies of Her2/neu proto-oncogene in human breast and ovarian cancer. Science 244 707-712, 1989.

2. Slamon DJ, Clark GM, Wong SG, Levin WJ, Ullrich and McGuire WL: Human breast cancer: correlation of relapse and survival with amplification of the HER-2/neu oncogene. Science 235: 177-182, 1987.

3. Andrulis IL, Bull SB, Blackstein ME, et al: Neu/erbB-2 amplification identifies a poor-prognosis group of women with node-negative breast cancer. Toronto Breast Cancer Study Group. J Clin Oncol 16: 1340-1349, 1998.

4. Press MF, Bernstein L, Thomas PA, et al: HER-2/neu gene amplification characterized by fluorescence in situ hybridization: poor prognosis in node-negative breast carcinomas. J Clin Oncol 15 2894-2904, 1997.
5. Ro JS, El-Naggar A, Ro JY, Blick M, Frye D, Fraschini G, Fritsche $\mathrm{H}$ and Hortobagyi G: C-erbB-2 amplification in node-negative human breast cancer. Cancer Res 49: 6941-6944, 1989.

6. Paterson MC, Dietrich KD, Danyluk J, et al: Correlation between c-erbB-2 amplification and risk of recurrent disease in node-negative breast cancer. Cancer Res 51: 556-567, 1991.

7. Duffy MJ: Predictive markers in breast and other cancers: a review. Clin Chem 51: 494-503, 2005.

8. Davoli A, Hocevar BA and Brown TL: Progression and treatment of HER2-positive breast cancer. Cancer Chemother Pharmacol 65: 611-623, 2010.

9. Quddus RM, Sung JC, Zhang C, Pasqueriello T, Eklund M and Steinhoff MM: Her2/neu expression in locally advanced breast carcinomas: pre- and post-neoadjuvant chemotherapy. Breast Cancer 12: 294-298, 2005.

10. Jones C, Ford E, Gillett C, et al: Molecular cytogenetic identification of subgroups of grade III invasive ductal breast carcinomas with different clinical outcomes. Clin Cancer Res 10: 5988-5997, 2004.

11. Van de Vijver M: Gene-Expression profiling and the future of adjuvant therapy. Oncologist 10: 30-34, 2005.

12. Hoff ER, Tubb RR, Myles JL and Procop GW: Her2/neu amplification in breast cancer: stratification by tumor type and grade. Am J Clin Pathol 117: 916-921, 2002.

13. Skálová H, Dundr P, Povýšil C, Velenská Z, Petruželka L and Tvrdík D: Study of the effect of neoadjuvant chemotherapy on the status of Her2/neu. Folia Biol (Praha) 57: 191-199, 2011.

14. Biéche I, Onody P, Laurendeau I, Martine O, Vidaud D, Lidereau $R$ and Vidaud M: Real-time reverse transcription-PCR assay for future management of ERBB2-based clinical applications. Clin Chem 45: 1148-1156, 1999.

15. Lyon E, Millson A, Lowery MC, Woods R and Wittwer CT: Quantification of HER2/neu gene amplification by competitive pcr using fluorescent melting curve analysis. Clin Chem 47: 844-851, 2001.

16. Riehle U, Mader A, Brandstetter T, Rühe J, zur Hausen A and Stickeler E: Nucleic acid sequence-based amplification in formalin-fixed and paraffin-embedded breast-cancer tissues. J Clin Pathol 63: 1071-1076, 2010. 